\title{
Efficacy and Safety of Duckbill Valve Voice Prosthesis in Comparison to Provox
}

\author{
Monoj Mukherjee, ${ }^{1}$ Siddhartha Das ${ }^{1}$
}

\section{Introduction:}

\section{$\underline{\text { ABSTRACT }}$}

Voice rehabilitation is the most important issue after total laryngectomy as source of vibration is removed. Three options are there like esophageal voice, electrolarynx and surgical prosthetic voice. Best is the prosthetic speech as voice is generated by lung powered air column. Provox prosthesis is the standard on and most commonly used. But it is costly for the class of patients presenting to our government hospitals. Duckbill prosthesis is very economical and may be helpful for them. There is very limited number of studies with duckbill prosthesis.

Materials and Methods:

Twenty two post-laryngectomy patients was selected for this study. Proper counselling was done regarding cost, pros and cons of Provox and Duckbill prosthesis. Fifteen patient selected Duckbill where as seven patient have chosen Provox prosthasis. Voice analysis was done after one month of speech therapy by perceptual voice analysis protocol. Safety and complications arising from prosthesis were also noted.

Results:

There was no significant difference in quality of voice.Both prosthesis are safe if prolong use is avoided.

Conclusion:

There is no significant difference in the quality and safety of both the prosthesis, but huge difference in cost is present. More over it is recurrent cost as it should be changed every year or earlier. One Provox costs around rupees fifty thousand whereas a duckbill prosthesis costs rupees one thousand approximately in Indian market.

Kevwords:

Laryngectomy; Voice; Prostheses and Implants

$\mathrm{C}$ arcinoma of larynx is generally treated with radiotherapy and NAC (Neo Adjuvant Chemotherapy). Stage 111 and $1 V$ disease require additional surgery. Most commonly performed surgery is wide field total laryngectomy with appropriate neck dissection.

Prognosis of total laryngectomy is better than many other forms of carcinoma, but it is a functionally destructive procedure needing voice substitution., ${ }^{1,2}$ Source of vibration should be substituted for verbal communication as larynx is removed. ${ }^{3}$ Different types of

1 - Department of ENT, NRS Medical College, Kolkata

\section{Corresponding author:}

Dr Siddhartha Das

email: docskdas@gmail.com prosthesis and devices are available in the market for that purpose. Provox ${ }^{\circledR}$ voice prosthesis is the standard one because of its safety and compatibility. It was developed in Netherland and it is being used all over the world most commonly. But it is costly.

The duckbill prosthesis was originally devised by Drs. Blom and Singer in 1978. It is not used commonly. But the major advantage was reduced cost of treatment which may be helpful to the patients of lower socio-economic class. However, as the data of efficacy of Duckbill prosthesis in comparison to Provox is limited, there is need of study that compares the two in terms of efficacy and safety. Hence this retrospective study was conducted to compare the speech outcome of Provox ${ }^{\circledR}$ and Duckbill prostheses following total laryngectomy. 


\section{Materials and Methods}

A retrospective study was done in the Department of ENT over a period of three years. Twenty two cases of total laryngectomy were selected for this study after informed consent. All were male except only one female patient. Their age ranges from 43 to 60 years (Table I). All the necessary investigations including biopsy, fibre optic laryngoscopy and CT scan of larynx and neck were done to ascertain the extent of disease before operation.

Laryngeal carcinoma of stage 111 or $1 \mathrm{~V}-\mathrm{A}$ were included in this study. Patients with poor general condition as assessed by through examination, spirometry and echocardiography were not selected for operation and excluded from this study. There were three cases, where voice could not be produced

Table I: Patient profiles

\begin{tabular}{|c|c|c|c|c|}
\hline CASE NO. & SEX & AGE & TNM STAGE & TYPE OF TEP \\
\hline 1 & Male & 46 & IV & Primary \\
\hline 2 & Male & 48 & III & Primary \\
\hline 3 & Male & 44 & III & Primary \\
\hline 4 & Male & 50 & IV & Secondary \\
\hline 5 & Male & 55 & III & Primary \\
\hline 6 & Male & 47 & III & Primary \\
\hline 7 & Male & 56 & IV & Primary \\
\hline 8 & Male & 58 & IV & Secondary \\
\hline 9 & Male & 43 & III & Primary \\
\hline 10 & Female & 46 & IV & Primary \\
\hline 11 & Male & 57 & III & Primary \\
\hline 12 & Male & 52 & III & Primary \\
\hline 13 & Male & 63 & IV & Secondary \\
\hline 14 & Male & 49 & IV & Secondary \\
\hline 15 & Male & 58 & III & Primary \\
\hline 16 & Male & 49 & IV & Primary \\
\hline 17 & Male & 61 & III & Primary \\
\hline 18 & Male & 55 & III & Secondary \\
\hline 19 & Male & 54 & IV & Primary \\
\hline 20 & Male & 50 & IV & Secondary \\
\hline 21 & Male & 44 & IV & Primary \\
\hline 22 & Male & 47 & III & Primary \\
\hline
\end{tabular}


after well fitting of prosthesis of different types. They were also excluded from this study and advised to use artificial larynx. All cases were sent to an adult speech therapist for preoperative counselling and training for post laryngectomy voice therapy

Conventional widefield total laryngectomy was done in 16 cases where neck nodes were not significant as judged preoperatively and during operation. Primary tracheo-esophageal puncture (TEP) was done in all these cases. Secondary TEP was done for 6 cases with significant neck nodes where modified neck dissections were necessary. Cricopharyngeal myotomy was performed in all the cases before closure.

Voice prosthesis was fitted after healing of wound. Regarding selection of valve, we considered economical condition of the patient. Proper counselling was done regarding initial and recurring expenditure for the prosthesis. Fifteen patients have chosen Duckbill voice prosthesis, where as remaining seven patient decided for Provox ${ }^{\circledR}$. Most of the Provox ${ }^{\circledR}$ prosthesis were fitted during operation and activated on third week after operation. Duckbill prosthesis was fitted after healing of wound, mostly after 3rd week of operation. Patients were advised to replace the prosthesis after six month or earlier for Duckbill type. Provox ${ }^{\circledR}$ prosthesis is changed every twelve month or earlier. Complications arising beyond this stipulated time were not included in this study

All the cases were sent to the care of an adult speech therapist. Their speech was assessed after two week of speech therapy. Finally they were called upon for recording of speech one month after fitting of voice prosthesis. By that time, they got habituated to the use of their speaking prosthesis. Fluent sentence speech was recorded by android phone. The recoded speech was sent for analysis to another speech therapist to avoid subjective biasness.

Post laryngectomy voice analysis was performed by speech and language pathologist. For this assessment two scheme were followed. First GRBAS scheme (Table II) and second was modified Buffalo-lll scheme.

Buffalo-1ll scale has so many parameters for assessment, like tone, pitch, nasal resonance, oral resonance, loudness, breath supply, muscles, voice abuse, rate, speech anxiety, speech intelligibility and overall rating. For simplicity of the study we have considered most important three parameters like pitch, loudness and overall grading. Here also a 4-point gradation was followed.

Safety of the prosthesis was judged over three parameters. First is dislodgement of the valve from the tracheo-esophageal fistula either into trachea causing aspiration or into the esophagus. Second is leakage of esophageal content into airway. Third parameter was infective damage of valve, mostly candida infection. The complications arising due to over use of the prosthesis were not included in this study. So the complications arose beyond six month and one year for Duck bill and Provox valve users respectively, were not considered for this study.

Table II: The GRBAS scheme - psychoacoustic impression and physiology ${ }^{5,6}$

\begin{tabular}{|c|c|}
\hline G- grade & Represents degree of hoarseness or voice abnormality(over all rating) \\
\hline R-roughness & $\begin{array}{l}\text { Represents psychoacoustic impression of irregularity of pitch and amplitude } \\
\text { and presence of spectral disharmony. }\end{array}$ \\
\hline B-breathy & $\begin{array}{c}\text { Represents psychoacoustic impression of the extent of air leakage during } \\
\text { phonation. }\end{array}$ \\
\hline A-asthenia & Represents weakness or lack of power in the voice \\
\hline S-strain & Represents psychoacoustic impression of a hyper functional state of phonation. \\
\hline
\end{tabular}

Evaluation: A 4-point grading is used for each scale: 0: Non-hoarse or normal; 1: Slight deviation from normal; 2 : Moderate deviation from normal; 3: Extremedeviation from normal 
Table III: GRBAS scale for Provox ${ }^{\circledR}$ users.

\begin{tabular}{|c|c|c|}
\hline $\begin{array}{c}\text { SERIAL } \\
\text { NO }\end{array}$ & GRBS SCALE & $\begin{array}{c}\text { TOTAL } \\
\text { SCORE }\end{array}$ \\
\hline 1 & G2R3B2A2S2 & 11 \\
\hline 2 & G2R2B2A2S2 & 10 \\
\hline 3 & G2R2B1A1S2 & 9 \\
\hline 4 & G2R3B2A2S3 & 12 \\
\hline 5 & G2R2B2A2S3 & 11 \\
\hline 6 & G2R2B2A2S2 & 10 \\
\hline 7 & G2R2B1A1S2 & 9 \\
\hline
\end{tabular}

\section{Results}

On GRBAS scheme, average score was 9.67 for the laryngectomees using Duckbill valve prosthesis. It was 10.3 for the laryngectomees using Provox ${ }^{\circledR}$ valve (Tables III and IV). Average score on modified Buffalo111 scale was 9.33 and 9 for those using Duckbill and Provox valve respectively.

Regarding safety, no adverse affect was found, provided the valves were changed within stipulated time. For Duckbill valve it is six month and Provox prosthesis it is one year.

The score 10 or less was achieved by $73.33 \%$ of patients with duckbill valve and $57.14 \%$ of patients with Provox valve.

\section{Discussion}

Laryngeal cancer contributes to $3-6 \%$ of all cancer in male in India. ${ }^{7,8}$ The age adjusted incidence rate of carcinoma of larynx in Indian male varies among registries. It has highest incidence (8.18 per 100000) in Kamprup urban district and the lowest incidence (1.26 per 100000) in Nagaland. ${ }^{7,8}$ Worldwide laryngeal carcinoma is the eleventh most common cancer in men but it is relatively uncommon in women. ${ }^{9}$

Most of the patients belong to low socioeconomic class as almost $70 \%$ of female and $50 \%$ of male patients were from illiterate or primary level education class. ${ }^{10}$
Table IV: GRBAS scale for Duckbill prosthesis users.

\begin{tabular}{|c|c|c|}
\hline $\begin{array}{c}\text { SERIAL } \\
\text { NO }\end{array}$ & GRBAS & TOTAL \\
\hline 1 & G2R2B2A2S2 & 10 \\
\hline 2 & G2R3B2A2S2 & 11 \\
\hline 3 & G2R2B2A1S2 & 9 \\
\hline 4 & G2R2B2A1S1 & 8 \\
\hline 5 & G2R2B2A2S2 & 10 \\
\hline 6 & G2R2B2A1S2 & 9 \\
\hline 7 & G2R2B2A2S2 & 10 \\
\hline 8 & G2R2B2A2S2 & 10 \\
\hline 9 & G3R2B2A2S2 & 11 \\
\hline 10 & G2R3B2A2S2 & 11 \\
\hline
\end{tabular}

The five year survival rate in India is $28 \%$ approximately which remains poor as compared to other Asian countries like Korea, China, and Singapore. ${ }^{11}$

Stage-1 and stage-1l disease is managed by concurrent chemotherapy and radiotherapy or endolaryngeal surgery. Stage-1ll disease is managed by either surgery or chemoradiotherapy. Stage-IV diseases are managed by surgery ${ }^{12}$ followed by radiotherapy or concurrent chemotherapy and radiotherapy. Different types of laryngectomy are in use, but total laryngectomy is most widely accepted. Prognostically it is a good operation when compared with surgical management of carcinoma in other region of body. ${ }^{1}$ But functionally it is a destructive procedure. ${ }^{2}$ Much body physiology is altered like voice production, swallowing, smelling, weight lifting etc. Most important is loss of voice production. As larynx is removed there is loss of vibrating air column which is essential for production of speech.

Laryngectomees can use surgical prosthetic voice, artificial larynx or esophageal voice. Artificial larynx is an electronic buzzing device and produced speech monotonous and metallic. It can be utilised for temporary purpose only. Esophageal voice is very hard to develop. Acquisition of good esophageal voice is around 30\% inspite of intense speech therapy. ${ }^{13}$ Among these, best option is surgical prosthetic voice as it is produced 
by pulmonary powered air column vibration in the reconstructed neopharyngeal-esophageal segment. ${ }^{9}$

Cricopharyngeal myotomy was done in all cases as it helps low pressure vibration in neo pharyngoesophageal segment. ${ }^{9}$

Complication like leakage was found in a case who used Provox ${ }^{\circledR}$ valve for one and half year which is beyond prescribed limit. Dislodgment of Provox valve into the trachea was also found in a case after twenty months of continuous use. It was remover by bronchoscopy. Two Duckbill valves dislodged to esophagus after one year of continuous use. These were passed with stool. These complications are not counted as they occurred due to over use of the prosthesis.

Voice analysis was done by perceptual voice analysis system. Two schemes were followed. In GRBAS scheme, Duckbill valve users had a better quality voice than Provox valve users. Whereas in modified Buffalo three scheme, Provox ${ }^{\circledR}$ users achieved marginally better voice.

A comparative study was done at Tata Memorial Hospital, Mumbai and at Command Hospital, Pune between Blom-Singer ${ }^{\circledR}$ Duckbill valve and Provox $^{\circledR}$ valve between 1996 to 1997 by Ramalingam et al. They have found better speech production by Provox ${ }^{\circledR}$ valve users. As per that study, fluent sentence speech was produced by $71.4 \%$ of Provox ${ }^{\circledR}$ valve users where as $70 \%$ of Duckbill valve users produced sentences with 10 words or more. ${ }^{13}$ Their speech analysis parameters are different than what we have used.

Delsupehe et al published a comparative study between Blom-Singer ${ }^{\circledR}$ and Provox ${ }^{\circledR}$ voice prosthesis for speech after total laryngectomy. ${ }^{14}$ They have found overall very similar voice quality, life time and patient satisfaction for both the groups. Cleaning management was somewhat better for Provox.

\section{Conclusion}

Efficacy of Duckbill valve is more on GRBAS scheme and marginally low on Buffalo-1ll scheme. Regarding safety, Duckbill valve is as good as Provox ${ }^{\circledR}$ valve. One Provox ${ }^{\circledR}$ valve costs around forty thousand where as one Duckbill valve costs less than one thousand! Moreover, this is a recurrent cost as this prosthesis has to be changed regularly.So in a country like India, Duckbill valve is selected by most of the patients if given choice.

\section{References}

1. Damste PH. Disorder of the voice. In: Alan G Kerr editor. Scott-Brown's Otolaryngology 5,6th edition. Butterworth Heineman, 1997; 5/6/1 - 5/6/25

2. Bloom et al. Tracheoesophageal voice restoration following total laryngectomy. London and San Diego: Singular Publishing, 1998:1-8

3. Alison Perry. Speech therapy in ENT practice: scope, science and evidence for intervention. In: Michael Gleeson, editor. Scott-Brown's Otolaryngology, Head and Neck Surgery 7th edition; 2227

4. RehanKazi et al. Voice restoration. In: John c Watkinson, Ralph W Gilbert, editors. Stell \& Maran's Textbook of Head and Neck Surgery and Oncology, 5th edition; 649-650

5. Omori $\mathrm{K}$ et al. Acoustic characteristics of rough voice: Subharmonics. Journal of voice. 1997;11:40-7

6. Takahasi $\mathrm{H}$ et al. Some perceptual dimension and acoustical correlates of pathological voices. Acta Otolarygologica, 1976;338:1-24

7. Saurabh Bobdey et al. Indian J Med Paediatroncol. 2015 julSep; 36(3): 154-160

8. Three-year report on population based cancer registries 20092011. Bangalore: National cancer registry programme (ICMR); 2013.ICMR. Individual registry wise annexure; pp 92-150

9. Birches et al. Tumours of the larynx. In: Michael Gleeson, editors. Scott-Brown's Otolaryngology , Head and Neck Surgery 7th edition; 2598-2619

10. Consolidated Reports on Hospital Based Cancer Registries 2007 -2011.Bangalore: National cancer registry programme (ICMR); 2013.ICMR. Education and Marital Status, religion and Language Spoken;pp.43-4tatus

11. Sankaranarayanan $\mathrm{R}$ et al: Cancer Survival in Africa, Asia, and Central America: A Population Based Study. Lancet oncol. 2010; 11:165-73. SurvCan

12. Kenneth Mackenzie and Hisham Mehenna. Larynx. . In: John C Watkinson, Ralph W Gilbert, editors. Stell \& Maran's Textbook of Head and Neck Surgery and Oncology, 5th edition; 649-650

13. Ramalingam et al. Tracheo-Esophageal Puncture (TEP) for Voice Rehabilitation in Laryngectomised Patients, BloomSinger Vs Provox Prosthesis: Our Experience. Med J Armed Forces India. 2007 Jan; 63(1):15-18

14. Delsupehe et al: Prospective randomized comparative study of tracheoesophageal voice prosthesis: Blom-Singer versus Provox. Laryngoscope 1998 October; 108(10):1561-5. 